\title{
Case Management in Primary Care for Frequent Users of Health Care Services: A Mixed Methods Study
}

\author{
Catherine Hudon, MD, PbD, CFPC $C^{1,2}$ \\ Maud-Cbristine Chouinard, RN, \\ $\mathrm{PbD}^{3,4,5}$ \\ Marie-France Dubois, $P_{b D^{6}}$ \\ Pasquale Roberge, $P b D^{1,2}$ \\ Christine Loignon, $\mathrm{PbD}^{1}$ \\ Éric Tchouaket, $P b D^{7}$ \\ Mireille Lambert, $M A^{3}$ \\ Émilie Hudon, RN, MSc $(c)^{3,4}$ \\ Fatoumata Diadiou, $\mathrm{MA}(\mathrm{c})^{3}$ \\ Danielle Bouliane, $M A^{3}$ \\ 'Département de médecine de famille et de \\ médecine d'urgence, Université de Sher- \\ brooke, Québec, Canada \\ ${ }^{2}$ Centre de recherche du Centre hospitalier \\ universitaire de Sherbrooke, Québec, Canada \\ ${ }^{3}$ Centre intégré universitaire de santé et de \\ services sociaux du Saguenay-Lac-Saint- \\ Jean, Québec, Canada \\ ${ }^{4}$ Département des sciences de la santé, \\ Université du Québec à Chicoutimi, \\ Québec, Canada \\ ${ }^{5}$ Centre de recherche de l'Hôpital Charles- \\ LeMoyne, Québec, Canada \\ ${ }^{6}$ Département des sciences de la santé \\ communautaire, Université de Sherbrooke, \\ Québec, Canada \\ ${ }^{7}$ Département des sciences infirmières, \\ Université du Québec en Outaouais, \\ Québec, Canada
}

\section{$8 m_{1}$ \\ MORE ONLINE \\ www.annfammed.org}

\section{AC}

Annals Journal Club selection; see inside back cover or http://www.ann fammed.org/AJC/.

Conflicts of interest: authors report none.

\section{CORRESPONDING AUTHOR}

Catherine Hudon, MD, PhD, CFPC

Département de médecine de famille et de médecine d'urgence

Université de Sherbrooke, Pavillon

Z7-local 3007

3001, 12e Ave Nord

Sherbrooke, Québec, J1H 5N4

Catherine.Hudon@usherbrooke.ca

\begin{abstract}
PURPOSE This study aimed to evaluate the effects of the V1SAGES case management intervention (Vulnerable Patients in Primary Care: Nurse Case Management and Self-management Support) for frequent users of health care services with chronic disease and complex care needs on psychological distress and patient activation.
\end{abstract}

METHODS We used a 2-phase sequential mixed methods design. The first phase was a pragmatic randomized controlled trial with intention-to-treat analysis that measured the effects of the intervention compared with usual care on psychological distress and patient activation before and after 6 months. The second phase had a qualitative descriptive design and entailed thematic analysis of in-depth interviews ( 25 patients, 6 case management nurses, 9 health managers) and focus groups (8 patients' spouses, 21 family physicians) to understand stakeholders' perceived effects of the intervention on patients.

RESULTS A total of 247 patients were randomized into the intervention group $(n=126)$ or the control group $(n=121)$. Compared with usual care, the intervention reduced psychological distress (odds ratio $=0.43 ; 95 \% \mathrm{Cl}, 0.19-0.95$, $P=.04)$, but did not have any significant effect on patient activation $(P=.43)$. Qualitative results suggested that patients and their spouses benefitted from the case management intervention, gaining a sense of security, and stakeholders noted better patient self-management of health.

CONCLUSIONS Together, our study's quantitative and qualitative results suggest that case management reduces psychological distress, making patients and caregivers feel more secure, whereas impact on self-management is unclear. Case management is a promising avenue to improve outcomes among frequent users of health care with complex needs.

Ann Fam Med 2018;16:232-239. https://doi.org/10.1370/afm.2233.

\section{INTRODUCTION}

Erear requent use of health care services is often driven by the complex 1 health and social care needs of individuals having chronic physical conditions and, often, mental health comorbidities, sometimes accompanied by social vulnerability. ${ }^{1,2}$ Frequent users with chronic disease and complex care needs often experience fragmented, uncoordinated, and ineffective health care, resulting in poor health outcomes at considerable costs to the health care system. ${ }^{3}$ Although high use may be defined from either a frequency or cost perspective, the former is more convenient and easier to measure when identifying this population in a pragmatic context. Given that primary care is a first point of contact with the health and social care system, it may play a strong role in allowing the implementation of innovations to provide more coordinated care. ${ }^{4}$

Different interventions have been developed and evaluated to improve care for frequent users of health care services, such as case management, individualized care plans, self-management support, and information sharing. ${ }^{5}$ Case management is the intervention most supported by evidence on improving appropriate use of health care resources, decreasing undue 
costs, and increasing patient well-being in this population. ${ }^{5-7}$ According to the Case Management Society of America, case management is "a collaborative process of assessment, planning, facilitation, care coordination, evaluation, and advocacy for options and services to meet an individual's and family's comprehensive health needs through communication and available resources to promote quality, cost-effective outcomes." ${ }^{8}$

Many reviews have documented the positive impacts of case management among frequent users of health care services. Althaus et $\mathrm{a}^{9}$ concluded that case management decreased emergency department use and costs, and improved clinical and social outcomes. Reviews by Kumar and Klein ${ }^{6}$ and Soril et $\mathrm{al}^{5}$ also reported that the majority of evidence pointed to the benefits of case management interventions for frequent users. Although findings of Stokes et $\mathrm{al}^{10} \mathrm{did}$ not support case management to reduce health care use and costs for the oldest at-risk patients, they did show improvement in patient satisfaction in the long term. Despite many studies on impacts of case management, however, no study has reported on psychological distress, a characteristic frequently found among frequent users, ${ }^{11-13}$ or on patient activation. ${ }^{14}$

This study aimed to evaluate the effect of the V1SAGES intervention (Vulnerable Patients in Primary Care: Nurse Case Management and Self-management Support), delivered by nurses in primary care, on psychological distress (primary outcome) and patient activation (secondary outcome) among frequent users of health care services with chronic disease and complex care needs.

\section{METHODS}

\section{Design}

We used a sequential explanatory mixed methods design, with consecutive quantitative and qualitative phases. ${ }^{15}$ The first phase was a pragmatic randomized controlled trial with delayed intervention for the control group and measurements before and after the 6 -month intervention. ${ }^{16}$ This phase of the study is reported according to the Consolidated Standards of Reporting Trials (CONSORT) guidelines. ${ }^{17}$ The second phase used a descriptive qualitative approach to gather a more comprehensive understanding of participants' experience with the case management intervention. ${ }^{18}$ This study was approved by the research ethics board of the Centre intégré universitaire de santé et de services sociaux du Saguenay-Lac-Saint-Jean, Quebec, Canada.

\section{Recruitment and Randomization}

Within a pragmatic context, we identified frequent users by combining metrics on frequency of use and health care professionals' judgment, according to current recommendations. ${ }^{19}$ All family physicians in 4 participating clinics received a list (generated by MAGIC Chronique software, MédiaMed Technologies ${ }^{20}$ ) of the top hospital services users. We defined frequent users as patients with 3 or more emergency department visits, hospitalizations, or some combination thereof in the previous 12 months. Family physicians then identified patients with complex care needs who they felt could benefit from the case management intervention and suggested additional patients who were frequent users of their clinic. Eligibility criteria required that patients be aged 18 to 80 years and have at least 1 chronic disease (diabetes, cardiovascular disease, respiratory disease, musculoskeletal disease, or chronic pain). Patients with serious cognitive problems were excluded.

Six nurses received 50 hours of theoretical and practical training on case management, including selfmanagement support techniques. The case management nurses contacted patients by telephone to ask if they were interested in participating. If a patient expressed interest, a research assistant telephoned the patient to explain the project, assess eligibility, and obtain consent. Participating patients were randomized into either the control or the intervention group according to a 1:1 ratio and based on a 3-stage randomization process: (1) generation of a random sequence using simple randomization, (2) provision of group allocations within sealed opaque envelopes, and (3) group allocation after patients' enrollment in the study. The investigators who collected the data were blinded to the assignation and were not involved in the randomization process.

\section{Intervention and Control Groups}

The intervention group received the V1SAGES case management intervention for 6 months. The intervention had 4 required components: (1) evaluation of patient needs and resources, (2) implementation and sustainability of an individualized service plan tailored to patients' priorities with the collaboration of the health care and community partners, (3) care coordination among the health care and community partners, and (4) provision of self-management support for patients and their families (eg, motivational interviewing)..$^{14,21-25}$ Each nurse had a maximum caseload of 50 patients.

Throughout the intervention, the case management nurse reassessed patients' needs and progress. Frequency of the contact depended on a patient's need. For the most part, these meetings were face to face, although the nurse was available to patients by telephone. Following the Stanford Chronic Disease SelfManagement program, the patients and their spouses 
were also invited to 6 weekly 2.5 -hour group meetings led by peer leaders. Meetings covered (1) techniques to deal with issues such as frustration, fatigue, pain, and isolation ${ }_{i}(2)$ appropriate exercise for maintaining and improving strength, flexibility, and endurance; (3) appropriate use of medications; (4) effective communication with family, friends, and health profession$\mathrm{als}_{i}(5)$ nutrition $_{i}(6)$ decision making; and (7) how to evaluate new treatments.

Any service that was provided to the patient in the intervention was reported to, or coordinated with, their family physician, and documented in their medical record. The case management nurse acted as the main point of contact and was informed of the patient's emergency department visits and hospitalizations during the intervention period.

Patients in the control group received the usual care from primary care nurses (not trained in case management) for 6 months (health promotion, global evaluation, follow-up of chronic diseases). Then, after data collection at that time, they received the V1SAGES 6-month case management intervention. ${ }^{26}$

\section{Quantitative Data Collection and Analysis}

Patient recruitment occurred from February 2013 to January 2014. At baseline, the research assistant administered the questionnaire to all patients at their primary care clinic and provided assistance as needed. Six months later, the research assistant collected outcomes data by telephone.

We assessed 2 outcomes: psychological distress measured with the Psychological Distress Scale (K6) ${ }^{27}$ and patient activation measured with the Patient Activation Measure (PAM). ${ }^{28,29}$ Psychological distress was analyzed as a dichotomous variable where scores of 13 or higher indicated the presence of psychological distress; patient activation was analyzed as a continuous variable. We also collected covariables at baseline to describe patient characteristics: (1) socioeconomic data (age, sex, marital status, education, occupation, economic status with family income, and perception of his/her economic situation), (2) health literacy, measured with the Newest Vital Sign (NVS) ${ }_{i}^{30}$ (3) mental health, measured with the Hospital Anxiety and Depression Scale (HADS) ${ }^{31,32}$; and (4) multimorbidity, measured with the Disease Burden Morbidity Assessment (DBMA). ${ }^{33,34}$

Treatment fidelity was assessed to determine whether the case management intervention was delivered as intended ${ }^{35}$ For this purpose, data regarding delivery of the 4 main components of the intervention were collected from the medical records. Treatment fidelity was expressed as the proportion of case management intervention components delivered.
We sought to recruit all frequent users who were eligible and agreed to participate in the study, estimating an average of 50 to 75 frequent users per clinic.

All statistical analyses were performed according to the intent-to-treat principle. Missing values at 6 months were imputed from baseline. We first confirmed that there was no intracluster correlation (no nurse-specific effect) and that multilevel analyses were not necessary. We then described the characteristics of patients in each group at baseline, using means and standard deviations (for continuous variables) or percentages (for categorical variables). Groups were compared on presence of psychological distress at 6 months using logistic regression analysis, adjusting for baseline presence of psychological distress. No other variable was included in this analysis because there were no stratification variables to take into account. ${ }^{36}$ Similarly, for patient activation, we compared group means at 6 months, adjusting for baseline scores, using analysis of covariance (ANCOVA). All statistical tests were performed with significance at the $5 \%$ level.

\section{Qualitative Data Collection and Analysis}

We contacted a sample of 69 key informants involved in the quantitative phase of this study to participate in individual semistructured interviews or focus groups after the 6 -month trial. A maximum variation sampling ${ }^{37}$ based on categories of participants, age, sex, and affiliated primary care clinic was used to capture a wide range of perspectives. In-depth semistructured individual interviews were conducted with 25 patients from the intervention group, 6 case management nurses, and 9 health managers. We also completed 3 focus groups with 8 patients' spouses and 4 focus groups with 21 family physicians. The 1 -hour interviews were conducted by an author trained in qualitative research (D.B.). The interview guide included open-ended questions and covered stakeholders' perception of the case management intervention. Interviews and focus groups were continued until data saturation was achieved.$^{38}$ The dialog was digitally recorded and transcribed verbatim.

Data were analyzed by 2 authors from different backgrounds (F.D., a graduate in social work, and M.L., a graduate in anthropology) using mixed coding as described by Miles et al. ${ }^{39}$ The reliability of the analysis was enhanced through data triangulation and peer debriefing during regular team meetings. NVivo 10 software (QSR International Pty Ltd) was used for qualitative analysis.

\section{Integration of Quantitative and Qualitative Data and Analyses}

The quantitative and qualitative findings were compared and contrasted through discussion among the authors. 
We considered and discussed convergent as well as divergent findings to achieve a more complete understanding of the effect of the case management intervention. ${ }^{15}$

\section{RESULTS}

\section{Quantitative Results}

Figure 1 shows the flow of patients through the trial. A total of 247 patients were recruited and completed the questionnaire at baseline ${ }_{i} 126$ patients were allocated to the intervention group, of whom 111 (88.1\%) completed the intervention. The intervention and control groups had similar baseline characteristics, as shown in Table 1. Overall, 230 (93.1\%) of the patients had follow-up through the study and completed the questionnaire at 6 months.

Case management nurses delivered each component of the intervention to patients as intended, demonstrating good intervention fidelity: $98.3 \%$ for patient evaluation, $94.8 \%$ for individualized care plan, $72.6 \%$ for care coordination, and $86.5 \%$ for self-management support.

Table 2 shows changes in prevalence of psychological distress and in level of patient activation. Compared with usual care, the intervention reduced the likelihood of psychological distress (odds ratio $=0.43 ; 95 \% \mathrm{CI}, 0.19-0.95, P=.04)$ but did not significantly alter patient activation (Cohen $d=0.17 ; P=.43$ ).

\section{Qualitative Results}

Characteristics of participants in the study's qualitative phase are presented in Supplemental Tables 1 and 2 (available at http://www.annfammed.org/ content/16/3/232/suppl/DC1/). The overall perception of stakeholders regarding the case management intervention was positive. Many of them noticed that improved accessibility and selfmanagement support gave patients and spouses a sense of security and helped patients to better self-manage their health, as discussed in more detail below.

\section{Improved Sense of Security}

The case management nurses were able to help improve patient access to professionals. Many patients and their spouses explained that this improved accessibility increased their sense of security, as exemplified by this comment from a 50-year-old woman:

It made me feel more secure, much more secure. I knew where I was going without going through... It's as if I felt secure, in the sense that I don't have to go through a 12-hour wait at the emergency department, because I have other ways (Patient 07, individual interview).
Figure 1. Flow of patients through the randomized trial.

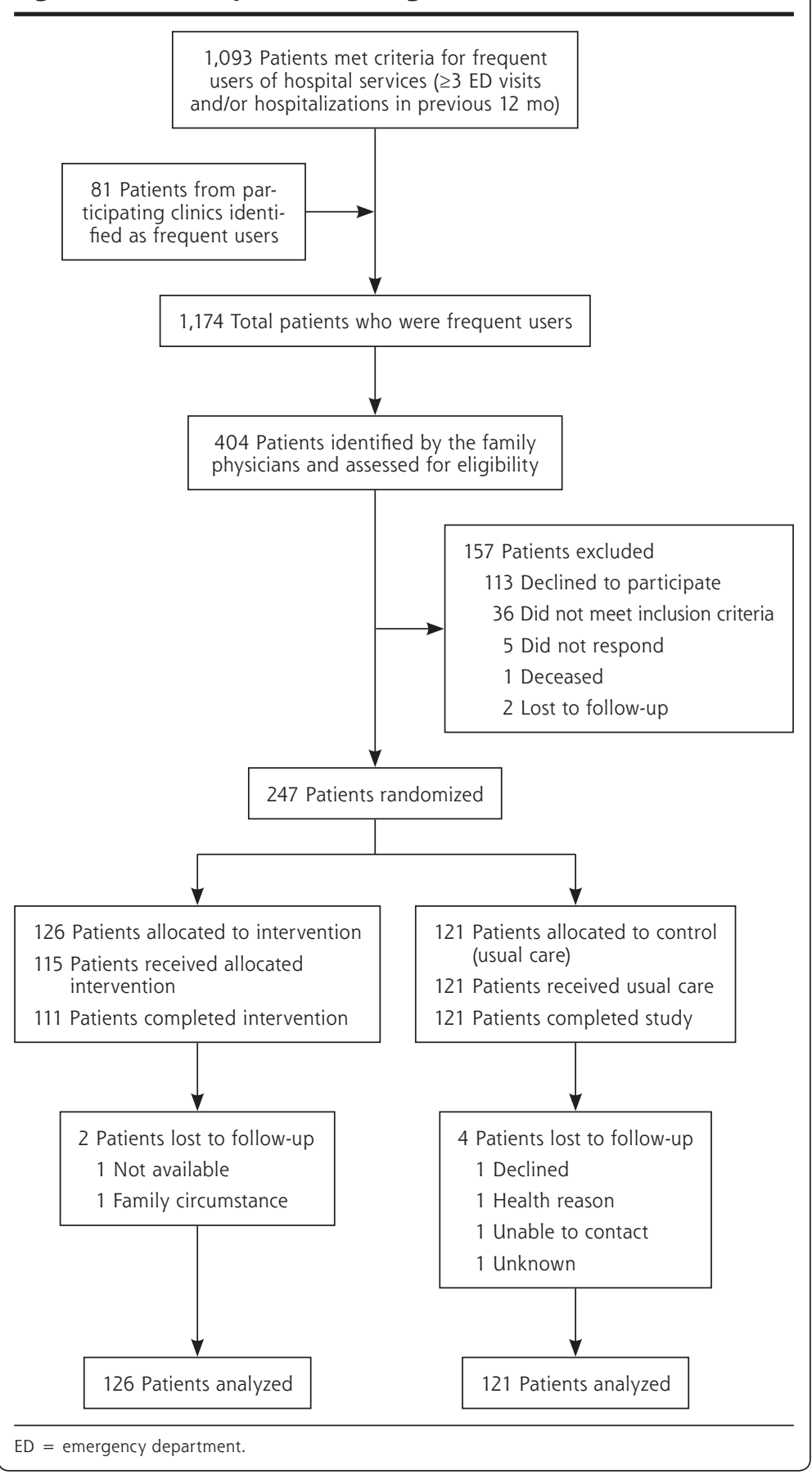


Table 1. Patients' Characteristics at Baseline, by Group

\begin{tabular}{|c|c|c|c|}
\hline Characteristic & $\begin{array}{l}\text { Intervention } \\
\text { Group } \\
(n=126)\end{array}$ & $\begin{array}{l}\text { Control } \\
\text { Group } \\
(n=121)\end{array}$ & $P$ Value \\
\hline Age, mean (SD), y & $61(13.5)$ & $59(12.9)$ & .14 \\
\hline Sex, male, No. (\%) & $58(46.0)$ & $44(36.4)$ & .12 \\
\hline Chronic conditions, mean (SD), No. & $5.8(2.7)$ & $6.1(2.7)$ & .38 \\
\hline Disease burden, DBMA score, mean (SD) ${ }^{\mathrm{b}}$ & $12.6(7.9)$ & $14.3(9.0)$ & .13 \\
\hline Married/living with a partner, No. (\%) & $80(63.5)$ & $75(62.5)$ & .22 \\
\hline Education, No. (\%) & & & .51 \\
\hline Not graduated from high school & $52(41.3)$ & $45(37.2)$ & \\
\hline $\begin{array}{l}\text { Graduated from high school or higher } \\
\text { education }\end{array}$ & $74(58.7)$ & $76(62.8)$ & \\
\hline Occupation, No. (\%) & & & .34 \\
\hline Work & $32(25.8)$ & $26(22.0)$ & \\
\hline Without work & $35(28.2)$ & $46(39.0)$ & \\
\hline Retired & $57(46.0)$ & $46(39.0)$ & \\
\hline Annual household income, No. (\%) & & & .11 \\
\hline$<\operatorname{Can} \$ 20,000$ & $32(26.4)$ & $38(31.4)$ & \\
\hline Can $\$ 20,000$-Can $\$ 49,999$ & $62(51.2)$ & $46(38.0)$ & \\
\hline$\geq \operatorname{Can} \$ 50,000$ & $27(22.3)$ & $37(30.6)$ & \\
\hline Perception of economic situation, No. (\%) & & & .20 \\
\hline Comfortable & $23(18.3)$ & $28(23.1)$ & \\
\hline Sufficient to meet their needs & $73(57.9)$ & $57(47.1)$ & \\
\hline Poor/very poor & $30(23.8)$ & $36(29.8)$ & \\
\hline $\begin{array}{l}\text { At risk for mental health problems } \\
\text { (HADS score } \geq 16)^{c} \text {, No. (\%) }\end{array}$ & $39(31.2)$ & $47(38.8)$ & .21 \\
\hline Low health literacy (NVS score <4), ${ }^{d}$ No. (\%) & $84(68.3)$ & $80(66.7)$ & .79 \\
\hline \multicolumn{4}{|c|}{$\begin{array}{l}\text { Can } \$=\text { Canadian dollars; DBMA = Disease Burden Morbidity Assessment; HADS = Hospital Anxiety and } \\
\text { Depression Scale; NVS = Newest Vital Sign. }\end{array}$} \\
\hline \multicolumn{4}{|c|}{$\begin{array}{l}\text { a Difference between groups assessed with a } t \text { test. } \\
\text { b DBMA scores range from } 1 \text { to } 48 \text {, with higher scores indicating greater disease burden. } \\
\text { ' HADS scores range from } 0 \text { to } 21 \text {, with higher scores indicating more severe anxiety and depression. } \\
\text { d NVS scores range from } 0 \text { to } 6 \text {, with higher scores indicating greater health literacy. }\end{array}$} \\
\hline
\end{tabular}

Table 2. Patients' Psychological Distress and Activation

\begin{tabular}{|c|c|c|c|c|}
\hline \multirow[b]{2}{*}{ Measure and Group } & \multicolumn{2}{|c|}{ Time Point } & \multirow{2}{*}{$\begin{array}{l}\text { AOR }(95 \% \mathrm{CI})^{\mathrm{a}} \\
\text { or Cohen } d^{\mathrm{b}}\end{array}$} & \multirow{2}{*}{$\begin{array}{c}P \\
\text { Value }\end{array}$} \\
\hline & Baseline & 6 Mo & & \\
\hline \multicolumn{5}{|l|}{$\begin{array}{l}\text { Psychological distress } \\
(\mathrm{K} 6 \text { score } \geq 13)^{c}\end{array}$} \\
\hline Intervention group, No. (\%) & $33(26.2)$ & $20(15.9)$ & $0.43(0.19-0.95)$ & .04 \\
\hline Control group, No. (\%) & $35(28.9)$ & $31(25.6)$ & (reference) & \\
\hline \multicolumn{5}{|l|}{ Activation (PAM score) ${ }^{d}$} \\
\hline $\begin{array}{l}\text { Intervention group, } \\
\text { mean (SD) score }\end{array}$ & $60.5(15.1)$ & $65.5(16.8)$ & 0.17 & .43 \\
\hline $\begin{array}{l}\text { Control group, mean } \\
\text { (SD) score }\end{array}$ & $63.0(15.6)$ & $65.4(16.3)$ & (reference) & \\
\hline
\end{tabular}

AOR = adjusted odds ratio; K6 = Psychological Distress Scale; PAM = Patient Activation Measure.

Note: Analyses based on 126 patients in intervention group, 121 patients in control group.

a From logistic regression analysis. Group comparison at 6 months adjusted for baseline psychological distress. ${ }^{b}$ From analysis of covariance (ANCOVA). Group comparison at 6 months adjusted for baseline score.

' $\mathrm{K} 6$ scores range from 0 to 24, with higher scores indicating greater psychological distress.

d PAM scores range from 0 to 100, with higher scores indicating greater activation. Scores can be categorized into 4 levels: Level 1 (score $\leq 47$ ), may not yet believe that patient role is important; Level 2 (score 47.1-55.1), lacks confidence and knowledge to take action; Level 3 (score 55.2-66.9), beginning to take action; Level 4 (score $\geq 67$ ), taking action.
Participants also observed that the case management intervention helped to reduce patient anxiety. Knowing that a trusted health care professional was present for them and was concerned about their condition was reassuring for patients. Reflecting on the impact of the case management intervention for one of his patients, a family physician said, "Even if she's still not totally autonomous, just being secure has led to her drinking less [alcohol]." (Family physician, focus group 04).

\section{Improved Self-Management}

Case management nurses explained that self-management support was an important part of the intervention. They were also careful to actively involve patients in decisions and objectives regarding their care:

The fact that they participate, that they express their point of view, that they say: "I agree/I disagree." We always let them decide. Then we respect what they want. And if he or she doesn't want [the service], it's not such a big deal. So it's as if there is better management, better involvement (Case management nurse 03, individual interview).

Patients, case management nurses, and family physicians perceived an improvement in patient knowledge and awareness due to the self-management support. One woman explained:

I would tell you, the kinesiologist, what she brought me. I got the whole package to try to lose weight, to balance my diet, the whole package to know what to do in practice especially (Patient 07, individual interview).

In addition, patients, their spouses, and case management nurses observed that patients showed increased self-efficacy and a feeling of greater control over their health: 
Oh yes! 'Cause I tend to give up quickly, then .... With that I followed ... it gives me more power. ... Then it helps me move forward, then to follow what I need to follow, my diet. And that helps me a lot (Patient 24, individual interview).

Case management nurses and physicians confirmed that they observed health improvement among their patients. As one described, "I have patients who lost weight, blood glucose levels improved, cholesterol levels improved." (Case management nurse 02, individual interview).

\section{DISCUSSION}

This mixed methods study is the first to evaluate the effect of case management on psychological distress and patient activation in primary care among frequent users having chronic disease and complex care needs. Our quantitative and qualitative findings are consistent regarding the benefit of the case management intervention on psychological distress and sense of security, but differ with respect to impact on self-management. Concordant as well as divergent findings from qualitative and quantitative data deserve further consideration. ${ }^{40}$

\section{Findings in Context}

The sense of security described by most of the interviewed patients and their spouses is consistent with the reduction in psychological distress observed in the pragmatic randomized controlled trial phase of this study. This finding is novel, and considering that frequent users tend to have higher psychological distress, ${ }^{11-13}$ this case management intervention is a promising avenue to enhance patients' sense of security by facilitating access to care, providing a single point of access, and developing close relationships between the patient and the case management nurse.

Our findings are consistent with results from previous studies of case management interventions for frequent users. A qualitative study by Grinberg et $\mathrm{al}^{41}$ on the key components of successful case management reported that the development of a healing relationship between clinicians and their patients was based on security, genuineness, and continuity of care. A nonrandomized but controlled study by Adam et $\mathrm{al}^{42} \mathrm{dem}$ onstrated an improvement in patient well-being after the implementation of a case management intervention by an interdisciplinary care team. In addition, the evaluation of a community matron service by Leighton et $\mathrm{al}^{43}$ found that a better access to health care services was related to patient confidence.

Participants in the qualitative phase of our study described improvement in patient self-management capacity. The qualitative study by Grinberg et $\mathrm{al}^{41} \mathrm{sim}$ - ilarly suggested that the healing relationship between clinicians and their patients, based on security, could motivate the patient to engage in self-management. Another study, by Chapman et al, ${ }^{44}$ with 31 health care professionals demonstrated that case management met patient needs through patient education about selfmanagement of their conditions.

The improvement in self-management described in these studies was not seen in our pragmatic randomized controlled trial, however. This difference could be partly explained by the fact that we used an instrument to measure activation, an outcome that has been shown to be important in the care of patients with chronic conditions, ${ }^{45}$ but not directly self-management. The PAM may have failed to capture changes in selfmanagement; thus, a more specific tool to measure this outcome (eg, the Partners in Health scale ${ }^{46}$ ) should be used in future studies. It is also possible that a 6-month follow-up period is not sufficient to observe a significant change in frequent users' self-management. ${ }^{6}$

Considering that $30 \%$ of intervention group patients had depression or anxiety symptoms at baseline, it is possible that it took a few months for case management to reduce their anxiety so that they could be receptive to self-management support. Indeed, patients with higher psychological distress could be less receptive to such support. ${ }^{47}$ Stakeholders perhaps began to note positive effect of the intervention on self-management for certain patients with less psychological distress or after reduction of their psychological distress, but more time would have been needed to capture this improvement in the trial.

\section{Strengths and Limitations}

Mixed methods designs provide a deep understanding of a complex intervention and its multidimensional factors. They use the strength of each method to get a more complete and accurate picture of the phenomenon. ${ }^{48}$ The quantitative phase of this study was strong in that pragmatic randomized controlled trials produce more reliable evidence compared with beforeand-after studies. The qualitative phase benefited from the varied backgrounds of the coauthors (family medicine, nursing, social work, and anthropology), which allowed for a rich triangulation of perspectives when analyzing the qualitative data. Moreover, the sample size of 69 participants was ample to reach data saturation. We used a recommended case-finding procedure (hospital data and health care professionals' opinions) to identify patients to participate in our case management intervention. ${ }^{19}$

At the same time, several limitations should be considered. During the case management intervention, 24 patients in the intervention group also participated 
in the Chronic Disease Self-Management Program. Although this is a small proportion of the control group, it could have introduced a cointervention bias. The 6-month evaluation period was too short to fully implement and evaluate such a complex intervention. Evaluating effect on services use and costeffectiveness would also have been interesting, but would have required a larger sample size. In addition, although the case management nurses had no contact with the control group, they may have unintentionally influenced other nurses who may have adopted a case management approach with the patients they cared for in the control group.

\section{Conclusions}

In conclusion, our findings suggest that the V1SAGES case management intervention reduces psychological distress, giving patients a greater sense of security. Many patients and stakeholders reported improvement in self-management capacity, but this impression did not translate into improved patient activation in the pragmatic randomized controlled trial. Case management holds promise for improving patient outcomes. Future studies could evaluate effect of the case management intervention on service use and costs, and also assess whether a longer intervention duration (1 year) would improve self-management.

To read or post commentaries in response to this article, see it online at http://www.AnnFamMed.org/content/16/3/232.

Key words: frequent users; utilization; case management; outcomes; mixed methods; comorbidity; practice-based research; primary care

Submitted June 28, 2017; submitted, revised, December 20, 2017; accepted January 19, 2018.

Funding support: This project was funded by the Pfizer-FRSQ-MSSS Chronic Disease Fund.

Disclaimer: None of the funding agencies-Pfizer, Fonds de recherche du Québec - Santé (FRQ-S), or Ministère de la santé et des services sociaux (MSSS) - was involved in collection, analysis, or interpretation of the data. They had no role in preparing, reviewing, or approving the manuscript.

Previous presentation: This study was presented as a poster at the North American Primary Care Research Group (NAPCRG) Annual Meeting; October 24-28, 2015; Cancun, Mexico.

Clinical trial registry: NCT01719991.

Acknowledgments: The authors thank Paula L. Bush and Susie Bernier for their editorial assistance and the patients who participated in the V1SAGES project, the CM nurses, and other stakeholders (patients' spouses, family physicians, and health managers).

Supplementary materials: Available at http://www.AnnFamMed. org/content/16/3/232/suppl/DC1/.

\section{References}

1. Hansagi $H$, Olsson M, Sjöberg S, Tomson Y, Göransson S. Frequent use of the hospital emergency department is indicative of high use of other health care services. Ann Emerg Med. 2001;37(6):561-567.

2. Byrne M, Murphy AW, Plunkett PK, McGee HM, Murray A, Bury G. Frequent attenders to an emergency department: a study of primary health care use, medical profile, and psychosocial characteristics. Ann Emerg Med. 2003;41(3):309-318.

3. Schoen C, Osborn R, Squires D, Doty M, Pierson R, Applebaum S. New 2011 survey of patients with complex care needs in eleven countries finds that care is often poorly coordinated. Health Aff (Millwood). 2011;30(12):2437-2448.

4. Starfield B, Lemke KW, Bernhardt T, Foldes SS, Forrest CB, Weiner JP. Comorbidity: implications for the importance of primary care in 'case' management. Ann Fam Med. 2003;1(1):8-14.

5. Soril LJ, Leggett LE, Lorenzetti DL, Noseworthy TW, Clement FM. Reducing frequent visits to the emergency department: a systematic review of interventions. PLOS ONE. 2015;10(4):e0123660.

6. Kumar GS, Klein R. Effectiveness of case management strategies in reducing emergency department visits in frequent user patient populations: a systematic review. J Emerg Med. 2013;44(3):717-729.

7. Raven MC, Kushel M, Ko MJ, et al. The effectiveness of emergency department visit reduction programs: a systematic review. Ann Emerg Med. 2016;68(4):467-483.e415.

8. Case Management Society of America. What is a case manager? http://www.cmsa.org/who-we-are/what-is-a-case-manager/. Accessed Jun 29, 2017.

9. Althaus F, Paroz S, Hugli O, et al. Effectiveness of interventions targeting frequent users of emergency departments: a systematic review. Ann Emerg Med. 2011;58(1):41-52.e42.

10. Stokes J, Panagioti M, Alam R, Checkland K, Cheraghi-Sohi S, Bower P. Effectiveness of case management for 'at risk' patients in primary care: a systematic review and meta-analysis. PLOS ONE. 2015;10(7):e0132340.

11. Grabe HJ, Baumeister SE, John U, Freyberger HJ, Völzke H. Association of mental distress with health care utilization and costs: a 5 -year observation in a general population. Soc Psychiatry Psychiatr Epidemiol. 2009;44(10):835-844.

12. Lin MT, Burgess JF Jr, Carey K. The association between serious psychological distress and emergency department utilization among young adults in the USA. Soc Psychiatry Psychiatr Epidemiol. 2012; 47(6):939-947.

13. Leporatti L, Ameri M, Trinchero C, Orcamo P, Montefiori M. Targeting frequent users of emergency departments: Prominent risk factors and policy implications. Health Policy. 2016;120(5):462-470.

14. Hudon C, Chouinard MC, Lambert M, Dufour I, Krieg C. Effectiveness of case management interventions for frequent users of healthcare services: a scoping review. BMJ Open. 2016;6(9):e012353.

15. Creswell J, Clarke V. Designing and Conducting Mixed Methods Research. 7th ed. Thousand Oaks, CA: SAGE Publications; 2007.

16. Patsopoulos NA. A pragmatic view on pragmatic trials. Dialogues Clin Neurosci. 2011;13(2):217-224.

17. Zwarenstein M, Treweek S, Gagnier JJ, et al; CONSORT group; Pragmatic Trials in Healthcare (Practihc) group. Improving the reporting of pragmatic trials: an extension of the CONSORT statement. BMJ. 2008;337:a2390.

18. Sandelowski M. What's in a name? Qualitative description revisited. Res Nurs Health. 2010;33(1):77-84.

19. Freund T, Gondan M, Rochon J, et al. Comparison of physician referral and insurance claims data-based risk prediction as approaches to identify patients for care management in primary care: an observational study. BMC Fam Pract. 2013;14:157. 
20. MédiaMed Technologies. Mesure de la performance: Logiciel MAGIC Chronique. Mont-Saint-Hilaire, Québec, Canada: MédiaMed Technologies.

21. Ross S, Curry N, Goodwin N; The King's Fund. Case Management: What It Is and How It Can Best Be Implemented. London, UK: The King's Fund; 2011.

22. Challis D, Hughes J, Berzins K, et al; University of Manchester. Self Care and Case Management in Long Term Conditions: The Effective Management of Critical Interfaces. London, UK: National Institute for Health Research Service Delivery and Organisation; 2010.

23. Freund T, Peters-Klimm F, Rochon J, et al. Primary care practicebased care management for chronically ill patients (PraCMan): study protocol for a cluster randomized controlled trial [ISRCTN56104508]. Trials. 2011;12:163.

24. Barlow J, Wright C, Sheasby J, Turner A, Hainsworth J. Selfmanagement approaches for people with chronic conditions: a review. Patient Educ Couns. 2002;48(2):177-187.

25. Miller WRRS. Motivational Interviewing: Preparing People for Change. 2nd ed. New York, NY: Guilford Press; 2002.

26. Steed L, Mulligan K, Newman S. Development and evaluation of self-management interventions. In: Newman S, Steed L, Mulligan K, eds. Chronic Physical Illness: Self-Management and Behavioral Interventions. Beckshire, UK: Open University Press; 2009:135-147.

27. Kessler RC, Andrews G, Colpe LJ, et al. Short screening scales to monitor population prevalences and trends in non-specific psychological distress. Psychol Med. 2002;32(6):959-976.

28. Skolasky RL, Green AF, Scharfstein D, Boult C, Reider L, Wegener ST. Psychometric properties of the patient activation measure among multimorbid older adults. Health Serv Res. 2011;46(2): 457-478.

29. Hibbard JH, Greene J. What the evidence shows about patient activation: better health outcomes and care experiences; fewer data on costs. Health Aff (Millwood). 2013;32(2):207-214.

30. Weiss BD, Mays MZ, Martz W, et al. Quick assessment of literacy in primary care: the newest vital sign. Ann Fam Med. 2005;3(6):514-522.

31. Zigmond AS, Snaith RP. The hospital anxiety and depression scale. Acta Psychiatr Scand. 1983;67(6):361-370

32. Bjelland I, Dahl AA, Haug TT, Neckelmann D. The validity of the Hospital Anxiety and Depression Scale. An updated literature review. J Psychosom Res. 2002;52(2):69-77.

33. Bayliss EA, Ellis JL, Steiner JF. Subjective assessments of comorbidity correlate with quality of life health outcomes: initial validation of a comorbidity assessment instrument. Health Qual Life Outcomes. 2005;3:51.

34. Poitras M-E, Fortin M, Hudon C, Haggerty J, Almirall J. Validation of the disease burden morbidity assessment by self-report in a French-speaking population. BMC Health Serv Res. 2012;12:35.
35. Dumas JE, Lynch AM, Laughlin JE, Phillips Smith E, Prinz RJ Promoting intervention fidelity. Conceptual issues, methods, and preliminary results from the EARLY ALLIANCE prevention trial. Am J Prev Med. 2001;20(1)(Suppl):38-47.

36. Kahan BC, Morris TP. Reporting and analysis of trials using stratified randomisation in leading medical journals: review and reanalysis. BMJ. 2012;345:e5840.

37. Crabtree BF, Miller WL. Doing Qualitative Research. Thousand Oaks, CA: Sage Publications Inc; 1999.

38. Sandelowski M. Sample size in qualitative research. Res Nurs Health. 1995;18(2):179-183.

39. Miles MB, Huberman AM, Saldaña J. Qualitative Data Analysis: A Methods Sourcebook. 3rd ed. London, UK: Sage Publications Inc; 2014.

40. Moffatt S, White M, Mackintosh J, Howel D. Using quantitative and qualitative data in health services research - what happens when mixed method findings conflict? [ISRCTN61522618]. BMC Health Serv Res. 2006;6:28.

41. Grinberg C, Hawthorne M, LaNoue M, Brenner J, Mautner D. The core of care management: the role of authentic relationships in caring for patients with frequent hospitalizations. Popul Health Manag. 2016;19(4):248-256.

42. Adam P, Brandenburg DL, Bremer KL, Nordstrom DL. Effects of team care of frequent attenders on patients and physicians. Fam Syst Health. 2010;28(3):247-257.

43. Leighton $Y$, Clegg A, Bee A. Evaluation of community matron services in a large metropolitan city in England. Qual Prim Care. 2008; 16(2):83-89.

44. Chapman L, Smith A, Williams V, Oliver D. Community matrons: primary care professionals' views and experiences. J Adv Nurs. 2009;65(8):1617-1625.

45. Wagner EH, Austin BT, Von Korff M. Organizing care for patients with chronic illness. Milbank Q. 1996;74(4):511-544.

46. Battersby MW, Ask A, Reece MM, et al. The Partners in Health scale: The development and psychometric properties of a generic assessment scale for chronic condition self-management. Aust J Prim Health. 2003;9(3):41-52.

47. Schulman-Green D, Jaser SS, Park C, Whittemore R. A metasynthesis of factors affecting self-management of chronic illness. J Adv Nurs. 2016;72(7):1469-1489.

48. Wisdom JP, Cavaleri MA, Onwuegbuzie AJ, Green CA. Methodological reporting in qualitative, quantitative, and mixed methods health services research articles. Health Serv Res. 2012;47(2):721-745. 